\title{
The fast response of Sahel precipitation to climate change allows effective mitigation action
}

\author{
Paul-Arthur Monerie $\mathbb{( D}^{1 凶}$, Benjamin Pohl $\mathbb{D}^{2}$ and Marco Gaetani (iD) ${ }^{3}$
}

Climate change will drive major perturbations of the West African summer monsoon. A zonal contrast in precipitation will develop at the end of the century, with an increase in precipitation over the central Sahel and a decrease in precipitation over the western Sahel. Such a zonal contrast results from the antagonist effects of the fast (due to enhanced radiative warming over land, and over the North Hemisphere, relative to the South Hemisphere) and slow (associated with long-term changes in oceanic circulation) responses of precipitation to increasing greenhouse gases. While such changes have already been assessed, less attention has been given to their temporality, an issue of major importance to promote efficient mitigation and adaptation measures. Here, we analyse the future evolution of precipitation changes decomposed into a fast and a slow response, showing that the fast response dominates the slow one. From this evidence, we highlight that mitigation strategies may be successful at reducing the effect of climate change on Sahel precipitation within a few decades, by muting the fast response. This decomposition also allows for a better understanding of the uncertainty of climate model predictions in Africa.

npj Climate and Atmospheric Science (2021)4:24 ; https://doi.org/10.1038/s41612-021-00179-6

\section{INTRODUCTION}

Climate simulations performed in the framework of the Coupled Model Intercomparison projects (CMIP3- $5^{1-3}$ ) show that the effects of anthropogenic activity on Sahel precipitation are highly uncertain. Models project either increases or decreases in Sahel precipitation by the end of the $21^{\text {st }}$ century ${ }^{4}$, with the inter-model spread in precipitation change exceeding the multi-model mean change ${ }^{5,6}$. Such uncertainty primarily originates from differences among climate models to simulate the response of the atmospheric circulation to changes in greenhouse gas (GHG) concentrations $s^{6,7}$. This model dependency also relates to uncertain changes in Sea Surface Temperature (SST), and more specifically to the northern-hemispheric differential warming and its effects over the Sahel ${ }^{6,8}$.

Even though Sahel precipitation change is quantitatively uncertain, a consensus emerges when only considering signs in precipitation evolutions $s^{4,9-11}$. Summer precipitation associated with the West African Monsoon is projected to increase over the central Sahel and to decrease over the western Sahel ${ }^{4,7,10-17}$. This evolution also prevails in CMIP6 simulations ${ }^{3}$ under the highemission SSP585 scenario ${ }^{6,18}$. The zonal contrast in precipitation changes strengthens with warming ${ }^{11}$, is reproduced by a majority of climate models and found in numerous emission scenar$\operatorname{ios}^{4,9,10,19-21}$. This precipitation change pattern has strong effects on local communities, as it is associated with heterogeneous impacts on agriculture 22 , occurrence of precipitation extreme events $^{23}$, modification of monsoon onset and withdrawal dates ${ }^{17}$.

The zonal contrast was suggested to result from two competing mechanisms, (i) the direct atmospheric effect of GHG increase, and (ii) the indirect response, mediated by the ocean through changes in $\mathrm{SST}^{10,20,24}$. The warming of the atmosphere yields a strengthening of the low-level moisture flux, a northward shift of the monsoon system and an increase in precipitation over the Sahel ${ }^{10,24}$. The increase of the SSTs leads to an increase in tropospheric static stability and subsidence over land, hereby favouring a decrease in Sahel precipitation ${ }^{10,24-26}$. Recent works speculated that these responses could add-up, explaining the zonal contrast in precipitation change 20,24 . However, both responses have two different timescales ${ }^{27,28}$, which overlap in a transient emission, with their relative contributions varying in time, obscuring our ability to understand the effects of the two responses on the future evolution of Sahel precipitation. We overcome this issue by using an approach which allows unravelling the timescale decomposition and drivers of Sahel precipitation changes. The decomposition allows highlighting the sources of uncertainty in Sahel precipitation change. We explore how the different timescales in Sahel precipitation change could display opportunities for effective and tangible mitigation of climate change over the Sahel.

\section{RESULTS}

\section{The timescale decomposition}

The response of precipitation to the warming of the atmosphere dominates changes that occur during the first ten years of an increase in $\mathrm{CO}_{2}$ concentration, and we then define this response as the fast response to climate change. The response that is due to a change in the oceanic circulation develops slowly than the fast response, and is hereafter defined as the slow response to climate change. We assess the fast response and the slow response to climate change, using idealized simulations in which $\mathrm{CO}_{2}$ concentration is abruptly quadrupled relative to pre-industrial control conditions (abrupt $4 \times \mathrm{CO} 2$ simulations) ${ }^{3}$. The fast response is the change that occurs at year 5-10 after abrupt $\mathrm{CO}_{2}$ quadrupling ${ }^{27}$ (see method). It is associated with an anomalously strong inter-hemispheric gradient (i.e. a stronger warming over the northern than over the southern hemisphere) and a strong warming over northern Africa (Fig. 1a). These changes lead the monsoon system to shift northwards and precipitation to increase (Fig. 1c) in July-August-September (JAS) ${ }^{8,29}$. The slow response is

\footnotetext{
${ }^{1}$ National Centre for Atmospheric Science (NCAS), Department of Meteorology, University of Reading, Reading, UK. ${ }^{2}$ Centre de Recherches de Climatologie, UMR 6282 Biogéosciences, CNRS/Université de Bourgogne Franche-Comté, Dijon, France. ${ }^{3}$ Scuola Universitaria Superiore IUSS, Pavia, Italy. ${ }^{凶}$ email: pmonerie@gmail.com
} 

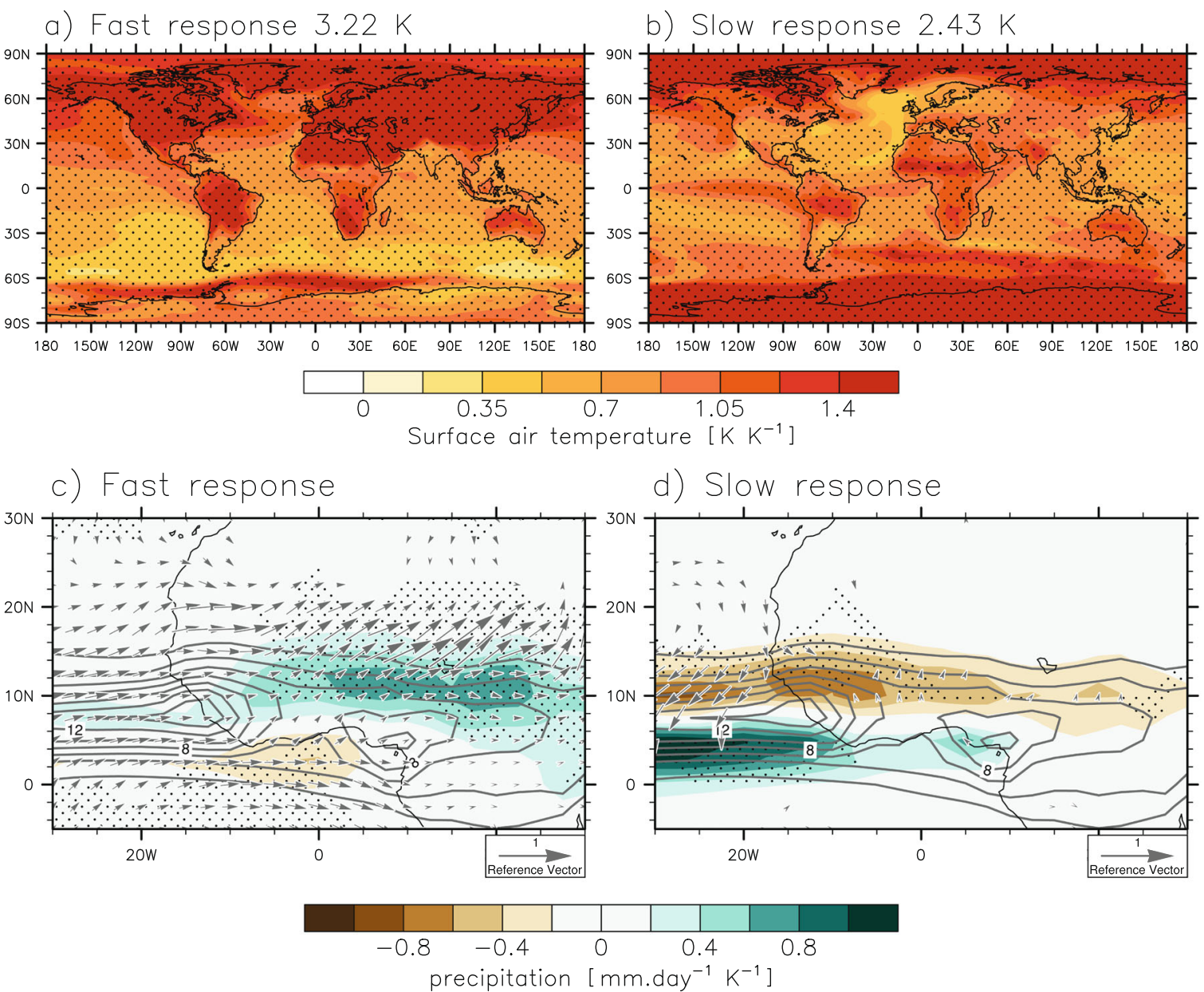

Fig. 1 Fast and slow responses to climate change. July-September mean temperature change $\left(\mathrm{K} . \mathrm{K}^{-1}\right)$ due to the $\mathbf{a}$ fast and $\mathbf{b}$ slow response to abruptly quadrupling $\mathrm{CO}_{2}$, and displayed by degree of warming level $(\mathrm{K})(\mathbf{c}, \mathbf{d})$, as in $\mathbf{a}$ and $\mathbf{b}$ but for precipitation change (colour, mm day ${ }^{-1}$ $\mathrm{K}^{-1}$ ) and surface wind change (arrows, $\mathrm{m} \mathrm{s}^{-1} \mathrm{~K}^{-1}$ ). On $\mathbf{c}$ and $\mathbf{d}$, contours indicate the average JAS precipitation, defined from pre-industrial control simulations. Stippling represents the grid-points where at least $80 \%$ of the models agree with the sign of the ensemble mean. 26 models were used.

defined as the change that occurs between year 5-10 and year 120-140 after quadrupling in $\mathrm{CO}_{2}$ concentration (i.e. years 120-140 minus years $5-10$ in abrupt $4 \mathrm{xCO}_{2}$ simulations) ${ }^{27}$ (see discussion in the Supplementary Discussion). After a century, the warming affects the ocean circulation, leading to changes over the Pacific Ocean, in a pattern reminiscent of El-Niño conditions (Fig. $1 \mathrm{~b})$, and of the Atlantic Multidecadal Variability (Supplementary Fig. 1). The slow response is associated with a substantial increase in global mean surface temperature (GMST), although lower than that for the fast response. It is also associated with a decrease in Sahel precipitation, and a southward shift of the monsoon system (Fig. 1d), thus leading to evolutions of opposite sign compared to the fast response.

Fast and slow patterns could be strongly sensitive to the definition method (see the discussion in the Material and Method). In addition, the slow and fast responses are associated with processes that can have feedbacks and interact with each other, and the two responses might not be fully independent. Moreover, both responses are associated with changes in temperature over land and over the ocean. Therefore, we verify such responses, and the respective roles played by the ocean and the land warming, using CMIP6 idealized atmosphere-only simulations ${ }^{30}$ (AMIP). We compare the fast response to simulations in which there is a quadrupling of the $\mathrm{CO}_{2}$ concentration, and the slow response to simulations in which a homogeneous increase of $4 \mathrm{~K}$ is added to each SST grid point, relative to a reference simulation (see Method for further details). The results of the idealized atmosphere-only simulations are shown in Supplementary Fig. 2. The direct effect of a quick warming acts to strengthen the moist static energy gradients across West Africa ${ }^{24}$, thereby strengthening the monsoon circulation and increasing precipitation, while the warming of the SSTs is associated with a weakening of the moist static energy gradients across West Africa, an increase in dry air intrusion from the North ${ }^{25}$ and a decrease in precipitation. Resulting patterns in precipitation change are similar in the idealized AMIP experiments to Fig. 1; therefore, we assume that the fast response is mostly associated with warming over land and the slow response with the warming of the ocean. In addition, these results show that the timescale decomposition is successful at extracting the specific features associated with the fast and slow responses.

\section{The evolution of the zonal contrast as a result of the fast and slow responses}

Any emission scenario can be considered as the sum of successive small abrupt-like forcings in consecutive years ${ }^{31,32}$. Hence, climate change always comprises fast responses to recently emitted GHGs, together with slow responses to previously emitted GHGs. We estimate the contributions of the fast and slow responses to GMST change by regressing the pattern of Fig. $1 a, b$ onto temperature anomalies, relative to the period 1960-1999, under both historical 

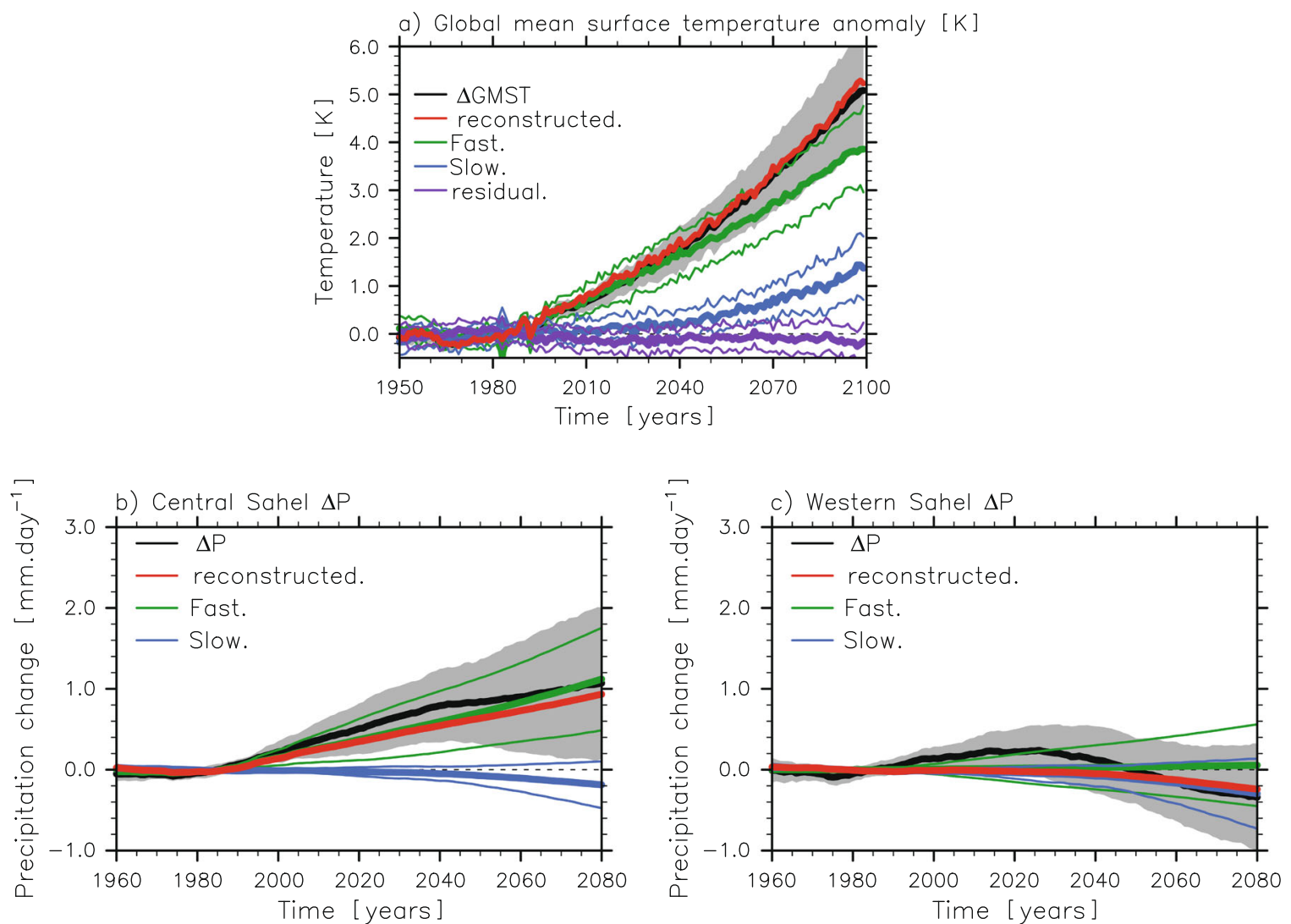

Fig. 2 Contribution of the two timescales responses to climate change. a Multi model mean contribution of the fast (green) and slow (blue) response to the global mean surface temperature warming (K) in SSP585 (black) (thick line). Residual is given by the purple line and the reconstruction (fast + slow) by the red line. Grey shading (thin lines) indicates the inter model spread, defined from each model, for the SSP585 response (fast, slow and residual responses). b Multi model mean change in central Sahel precipitation (mm day ${ }^{-1}$ ) for SSP585 response (black), fast (green), slow (blue) and reconstructed (red) responses. c as in b but for western Sahel and eastern Atlantic Ocean. Highfrequency variability anomalies are filtered-out with a 21-year running mean.

and SSP585 emission scenario (see material and method). A spatial multiple linear regression is performed for each JAS season between 1950 and 2099. The regression coefficients document the respective contributions of the fast and slow responses to total temperature changes, with the intercept considered as a residual ${ }^{27}$. The fast response increases rapidly over the $21^{\text {st }}$ century and primarily contributes to changes in GMST (Fig. 2a). The slow response increases later, and, under the SSP585 emission scenario, explains $\sim 25 \%$ of the GMST anomaly at the end of the $21^{\text {st }}$ century. We then reconstruct GMST changes by summing the fast and slow responses. The reconstructed response is similar to the SSP585 GMST change, showing a good ability of the decomposition method to reproduce GMST change, with a rather low residual (Fig. 2a).

Figure $2 \mathrm{~b}$ shows that central Sahel precipitation $\left[10^{\circ}-20^{\circ} \mathrm{N} ; 5^{\circ} \mathrm{W}\right.$ $20^{\circ} \mathrm{E}$ ] increases throughout the $20^{\text {th }}$ and $21^{\text {st }}$ century. We define fast and slow responses in precipitation changes by scaling precipitation anomalies of Fig. 1c, d with the regression coefficient computed from GMST changes (Fig. 2a) ${ }^{28}$ (see Material and Method). Although it underestimates the magnitude in precipitation change, the reconstructed precipitation change follows remarkably well the full SSP585 response. Central Sahel precipitation increases with warming, due to a predominant impact of the fast response, while the slow response yields moderate and negative precipitation changes. Over the western Sahel and the tropical Atlantic $\left[10^{\circ}-20^{\circ} \mathrm{N} ; 30^{\circ} \mathrm{W}-10^{\circ} \mathrm{W}\right]$, precipitation decreases mostly due to the slow response (Fig. $2 \mathrm{c}$ and Supplementary Fig. 3 ). The reconstruction is less accurate for low levels of warming (Fig. 2c). This is expected to be due to a low signal-to-noise ratio for weak warmings, particularly over the western Sahel ${ }^{33}$, but could also be due to anthropogenic aerosols ${ }^{34}$, whose effects are not accounted in the timescale decomposition used here. Over the western Sahel, the reconstruction method accurately reproduces the full impact of climate change for GMST increases of more than $2 \mathrm{~K}$, i.e. from 2050 onwards (Fig. 2a, c). We show the anomalies in precipitation associated with fast and slow responses for a GMST warming of $3 \mathrm{~K}$ (i.e. selecting a 20-year interval around the time when a 20-year running mean hits $+3 \mathrm{~K}$ for each individual model), because several individual models do not simulate warmings of $4 \mathrm{~K}$. The fast response is associated with an increase and northward shift in Sahel precipitation (Fig. 3a). The slow response leads to a southward shift of the circulation over the Sahel and the tropical Atlantic Ocean (Fig. 3b), in line with a warming that is higher over the tropical than the subtropical north Atlantic (Fig. 1b and Supplementary Fig. S1b). Changes are considered as robust, because they are reproduced by at least $80 \%$ of the models (i.e. 26 models). The moderate magnitude of the slow response, with regard to the fast one, explains why changes in precipitation are stronger and grow quicker over the central than over the western Sahel ${ }^{33,35}$.

The "reconstructed" response (fast + slow responses) fully explains the zonal contrast in precipitation change (Fig. $3 \mathrm{C}$ ) that is obtained in the SSP585 emission scenario (Fig. 3d). For illustration purposes, the pattern correlation between raw precipitation changes under SSP585 scenario and the reconstruction method yields a value of 0.97 (over the $5^{\circ}-25^{\circ} \mathrm{N}$ and $20^{\circ} \mathrm{W}-30^{\circ}$ E domain). The zonal contrast in precipitation change is therefore due to two antagonist mechanisms, with the increase in land 
a) Fast $3 K 2058-2077$



c) Fast + slow 3K

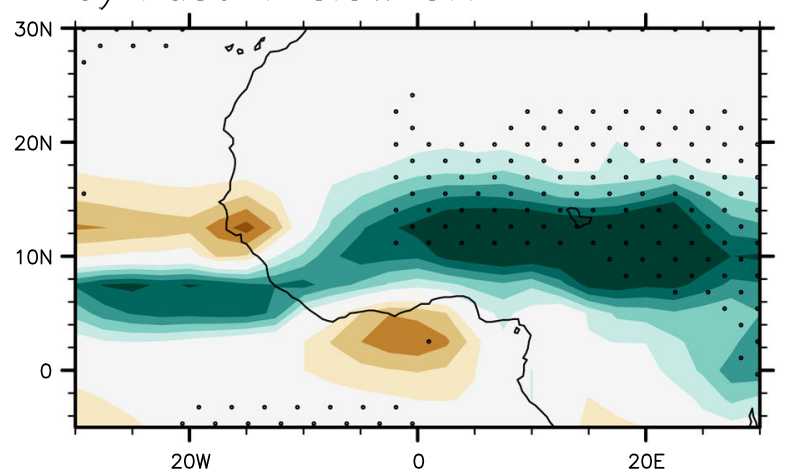

b) Slow 3K

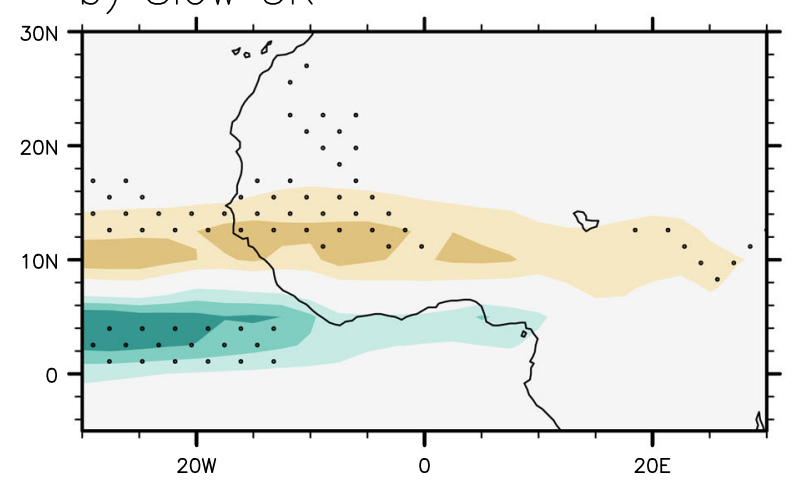

d) SSP585 3K

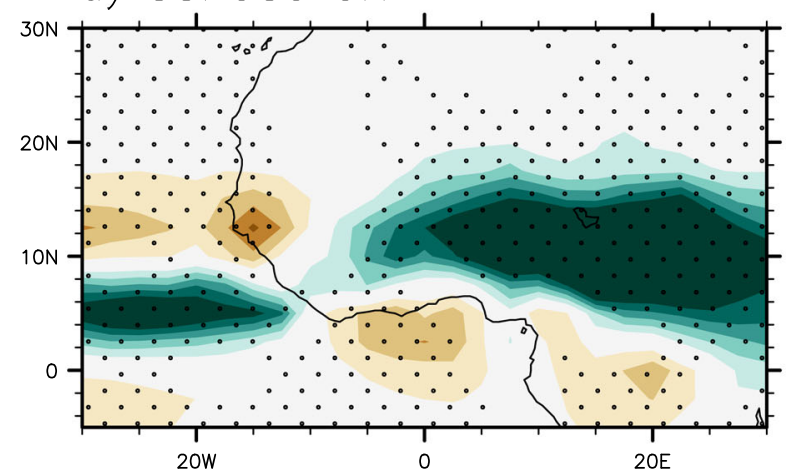

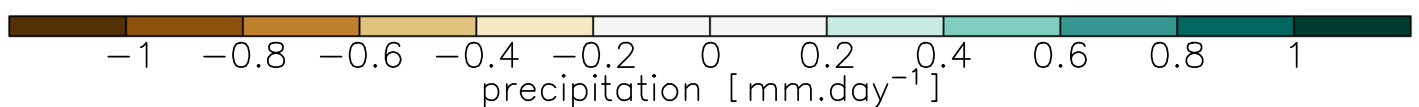

Fig. 3 The zonal contrast is due to the addition of the two antagonists fast and slow responses. Multi model mean of the $\mathbf{a}$ fast and $\mathbf{b}$ slow responses, $\mathbf{c}$ their addition and the $\mathbf{d}$ total SSP585 response, for warmings of $3 \mathrm{~K}$, relative to the period 1960-1999. Stippling represents the grid-points where at least $80 \%$ of the models agree with the sign of the ensemble mean.

temperature and the strengthening of the inter-hemispheric gradient leading to an increase in central Sahel precipitation (Fig. 1a, c), and the warming of the tropical ocean, with no increase in inter-hemispheric gradient, reducing monsoon rainfall in the western Sahel (Figs. 2b and 3a).

\section{A mitigation scenario}

The decomposition of the precipitation response shows that the fast response is prominent over the central Sahel. This suggest that a sharp inflexion in GHG emission could have rapid repercussions. We test this hypothesis using the SSP534_over emission scenario, which follows the SSP585 emission scenario until 2040, and with GHG emissions decreasing abruptly afterwards, to reach a radiative warming of $3.4 \mathrm{~W} \mathrm{~m}^{-2}$ at the end of the $21^{\text {st }}$ century $^{18}$. As a consequence, GMST decreases after 2060, mainly due to the fast response (Fig. 4a), while the slow response becomes steady. Like GMST, the central Sahel precipitation does not increase after 2050-2060, materializing the ending influence of the fast response (Fig. 4b). The slow response still increases linearly with time over the central Sahel, showing no clear impacts of a reduction in GHG emissions (Fig. 4b). Over the western Sahel, precipitation continues to decrease continuously after 2040, which is only attributed to the slow response, while the fast response yields negligible anomalies (Fig. 4c). The reconstruction method works satisfactorily for central Sahel precipitation, but is not able to account for the magnitude of precipitation changes in the western Sahel, even if it captures well its decreasing trend. Therefore, the effect of a mitigation strategy is shown by comparing changes between the SSP585 and SSP534_over emission scenarios, focusing on central Sahel precipitation. The effect of a mitigation strategy is strong at the end of the $21^{\text {st }}$ century and is mostly due to the fast response (Fig. 4d), mediated by changes in regional-scale moisture convergence (Fig. 4f), while differences in evaporation are moderate between the two scenarios (Fig. 4e). These results highlight that reducing global GHG emission would rapidly lead to a weakening of the impact of climate change over the Sahel.

Evolution in western Sahel precipitation is primarily driven by the slow response (Fig. 2c) and might therefore not be significantly impacted by a sudden inflexion in GHG emission before the end of the $21^{\text {st }}$ century. However, we acknowledge that differences over the western Sahel are strong between the two emission scenarios, but cannot be attributed to either the fast or slow responses (Supplementary Fig. 4). They are due to a strong increase in moisture flux convergence (Supplementary Fig. 4) under a mitigation scenario, and local changes in temperature and circulation that poorly scale to the global pattern of the fast and slow responses, likely in line with changing SST over the tropical Atlantic Ocean (Supplementary Fig. 58).

We acknowledge that, in addition to a decrease in monthly mean precipitation, a mitigation strategy might lead to a change in extreme events, by reducing the surface air temperature gradient across the Sahel (Supplementary Fig. 5), which is connected to intense storms ${ }^{36,37}$. Effects of a mitigation strategy could also be due to differences in anthropogenic aerosol, whose emissions partly explain seesaws in Sahel precipitation ${ }^{38,39}$. However, the main difference between the two emission scenarios is the trajectory in $\mathrm{GHG}$ emissions ${ }^{18,40}$, which is therefore the main 

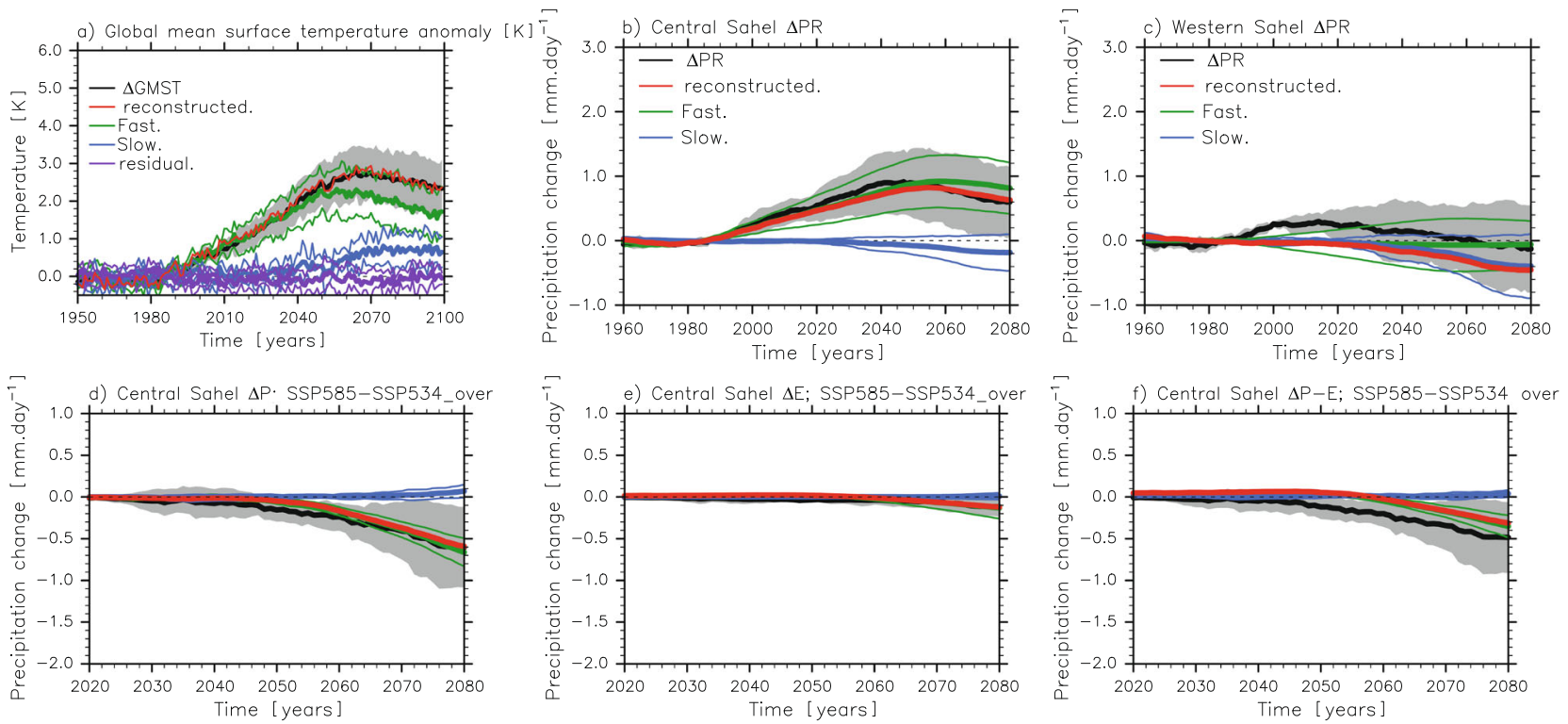

Fig. 4 A mitigation strategy. a Multi model mean contribution of the fast (green) and slow (blue) response to the global mean surface temperature warming (K) in SSP534_over (black) (thick line). Residual is given by the purple line and the reconstruction (fast + slow) by the red line. Grey shading (thin lines) indicates the inter model spread, defined from each model, for the SSP534_over response (fast, slow and residual responses). b Multi model mean change in central Sahel precipitation ( $\mathrm{mm} \mathrm{day}^{-1}$ ), for SSP585 response (black), fast (green), slow (blue) and reconstructed (red) responses. $\mathbf{c}$ as in b but for western Sahel and eastern Atlantic Ocean. SSP534_over - SSP585 difference in d precipitation, e evaporation and $\mathbf{f}$ P-E for central Sahel. High-frequency variability anomalies are filtered-out with a 21-year running mean. 7 models were available for the SSP534_over emissions scenario. 7 models are used for the SSP534_over - SSP585 differences.

cause for the differences between the SSP585 and SSP534_over emission scenarios.

\section{Decomposing uncertainty in precipitation change}

Uncertainties in Sahel precipitation change are large ${ }^{5,6}$, preventing clear guidance in future policies that would be applied to face climate change effects. We step forward at understanding uncertainties by separating their causes, according to their timescale responses. We define uncertainties by first applying a 21-year running mean to the precipitation time series, for consistency with results of Fig. 2, and for reducing the stochastic high-frequency variability. For a given emission scenario, uncertainties are caused by differences in model's parameterization and to internal climate variability, which is unlikely to be phased among simulations ${ }^{41}$. Internal climate variability is known to be large over the Sahel ${ }^{33}$. It is defined here as the variance of a 21year running mean in Sahel precipitation anomalies, for each model, using the pre-industrial control simulations (i.e. in absence of anthropogenic forcing $)^{42}$. Uncertainty due to internal climate variability is then assessed as the multi-model ensemble mean of the 21-year variances, and is considered constant throughout $20^{\text {th }}$ and $21^{\text {st }}$ century. This leads to a good approximation of internal climate variability in a warmer climate, which has been shown to not dramatically change over the course of the $21^{\text {st }}$ century ${ }^{33}$. Finally, model uncertainty is assessed through computing the inter-model variance in both the fast and slow responses. We define the SSP585 fast and slow model uncertainties using one ensemble member for each model. The response of each model might therefore be influenced by its internal climate variability. However, the reconstruction method and the multi-model mean reduce internal variability (see smoothed fast and slow responses on Fig. 2b, c). Moreover, we fit a fourth-order polynomial and retain the smoothed fit as fast and slow responses, with no effects of internal climate variability, for each model ${ }^{41}$. Lastly, we verify that internal climate variability does not impact the results by performing the analysis with ensembles of several members. This confirms that the method filters out most of internal variability
(Supplementary Fig. 6). Results have been replicated using a 10year running and with no filtering, giving the same conclusion than with the 21-year running mean (Supplementary Fig. 7).

Figure $5 \mathrm{a}$ shows the relative contributions of the three sources of uncertainties (i.e. fast, slow and internal variability) over the central Sahel. Total uncertainty is defined as the sum of all three aforementioned sources. Over years 1960-2000, uncertainty primarily corresponds to internal climate variability (Fig. 5a). Fast response uncertainty is the largest after 2000, implying that the main source of Sahel precipitation uncertainty, in a transient climate, relates to its fast-responding component (Fig. 5a). The relative weight of the slow response uncertainty grows with time, but stays moderate with regard to the fast response (Fig. 5a). When considering absolute uncertainties, both fast and slow response uncertainty grow with time, with the slow response uncertainty increasing 30 years after the fast response (Fig. 5b). Such 30-year delay is consistent with the simulated temporality in precipitation changes (Fig. $2 \mathrm{~b}-\mathrm{c}$ ). The same behaviour is obtained using the SSP534_over scenario, except that the reduction in post2040 GHG emission is associated with a rapid decrease in uncertainties associated with the fast response (Fig. 5b). Unlike the fast response, uncertainty associated with the slow response continues to grow until 2100 . At the end of the $21^{\text {st }}$ century, the fast/slow uncertainty ratio is higher with the SSP585 than with the SSP534_over emission scenario, showing that sources of uncertainty strongly depend on the evolution in GHG emissions. Over the central Sahel, the increase in GMST coincides with an increase in precipitation, and with more frequent extreme events ${ }^{23,35,36}$. A decrease in GHG emissions could weaken the effects of climate change and uncertainty over the Sahel, with a 30-year delay that could relate to the residence time of $\mathrm{CO}_{2}$ in the atmosphere, and/ or to the thermal and dynamic inertia of oceanic circulation.

\section{DISCUSSION}

CMIP6 models project onto a strengthening of a zonal contrast, with an increase in precipitation over the central Sahel and a decrease in precipitation over the western Sahel. While anomalies 

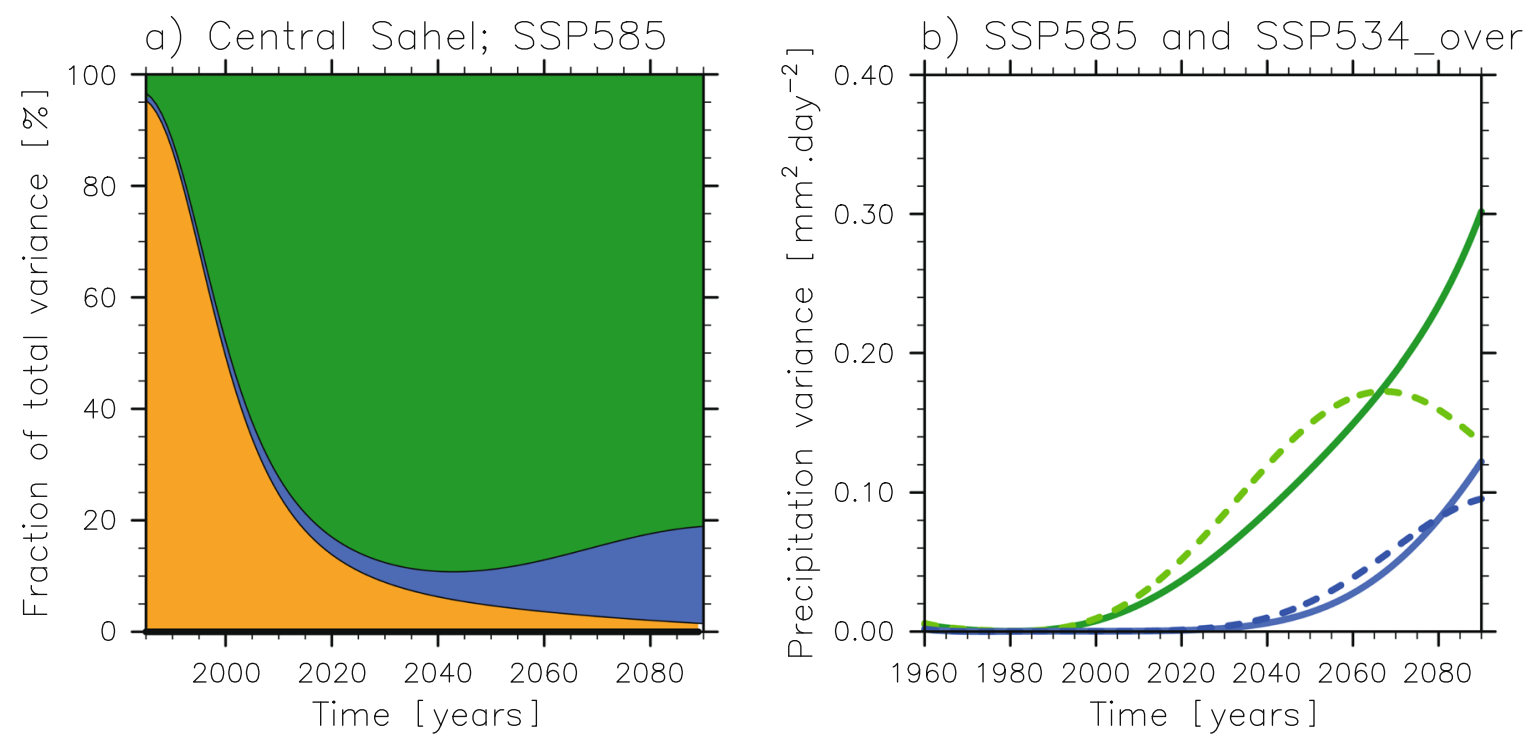

Fig. 5 Reducing uncertainty in central Sahel precipitation change. a Fraction of the total uncertainty in 21-year running mean precipitation, as defined from the sum of fast (green), slow (blue) and internal climate variability (orange) uncertainties, for central Sahel precipitation. Fast and slow uncertainties are defined from the inter model variance in fast and slow components of precipitation change, first smoothed by fitting a fourth-order polynomial. Internal climate variability is defined from multi model average of 21-year precipitation variance, first computed for each model, using pre-industrial control simulations. Values are plotted at the central year of the 21-year moving window. b Absolute inter model variance in fast response (green) and slow response (blue) for the SSP585 (continuous line) and SSP534_over (discontinuous line) emission scenarios. 26 models are used in a and 7 models are used in $\mathbf{b}$.

show two poles emerging at the end of the $21^{\text {st }}$ century $6,33,35$, we show that precipitation changes in western and central Sahel are linked to different mechanisms, that changes on different time scales. Central Sahel precipitation change is associated with the fast response to climate change, and occurs at a higher rate than that for western Sahel precipitation, which is associated with the slow response to climate change, at the end of the $21^{\text {st }}$ century. Understanding the timing of these anomalies is a key aspect of any mitigation strategy in the region, allowing a better anticipation of changes in Sahelian countries (e.g. extreme event ${ }^{23}$, heat waves $^{43}$, changes in well-being ${ }^{44,45}$, agricultural yield $\left.{ }^{46}\right)$, which are among the most vulnerable countries to climate change. We show that a strong mitigation scenario would substantially reduce the climate change impact over West Africa, with a 30-year delay after the reduction in $\mathrm{CO}_{2}$ emission. The high effectiveness of such mitigation strategy finds is rational in the fast response to climate change, which develops over the 10 years after a change in $\mathrm{CO}_{2}$ concentration and which primary explains the projected change in central Sahel precipitation. A mitigation strategy would therefore be successful at reducing the effect of climate change on Sahel precipitation, consequently reducing its effects on the society. We analyse monthly means in precipitation, but assume that a mitigation strategy would be also successful at reducing precipitation extreme events, which are associated with storms, by reducing the northern African temperature gradient ${ }^{36,37}$. In addition, we show that the first source of uncertainty in precipitation change is associated with the fast response, which is model-dependent (Supplementary Fig. 8) and decreases quickly when adopting a mitigation scenario. This leads to an increased confidence in climate projections. This also stresses the need for understanding better the causes of the inter-model spread in precipitation and temperature change within a decade after an increase in $\mathrm{CO}_{2}$ emission. The SSP534_over emission scenario models an aggressive mitigation strategy ${ }^{18}$. However, we highlight that a coordinated international effort in reducing global emissions is successful at robustly mitigating effects of climate change in Sahelian countries within a predictable time horizon. In this respect, the demonstrated effectiveness of the mitigation strategies unambiguously highlights the need for immediate and substantial action ${ }^{47}$.

\section{METHODS}

\section{CMIP6}

The study is based on the analysis of multiple experiments from CMIP6 ${ }^{3}$. Please see Tables 1 and 2 in Supplementary Tables for a list of models, institutions and references.

\section{AMIP experiments}

The climate response to the direct $\mathrm{CO}_{2}$ forcing is analysed using the amip $4 \times \mathrm{CO}_{2}$ simulations. amip $4 \mathrm{xCO}_{2}$ are atmosphere-only simulations, which last for 36 years, in which SSTs and sea ice concentration are held at control values and $\mathrm{CO}_{2}$ as seen by the radiation scheme, is quadrupled $^{30}$. The effect of a warming ocean is analysed using the amip-p4K experiment, where SSTs are subject to a uniform warming of $4 \mathrm{~K}$, with $\mathrm{CO}_{2}$ concentration held at control values. amip4xCO2 and amip-p4K are compared to the AMIP reference simulation, where both SSTs, sea ice and $\mathrm{CO}_{2}$ are prescribed at observed 1979-2014 values ${ }^{30}$, and vary with time. Anomalies are computed over the JAS period. 10 models were available for AMIP experiments, see Supplementary Table 1.

\section{Abrupt4xCO2 experiments}

We assess the effects of a strong and fast increase in $\mathrm{CO}_{2}$ forcing by using the abrupt $4 \times \mathrm{CO}_{2}$ experiments. abrupt $4 \times \mathrm{CO}_{2}$ are simulations performed with CMIP6 ocean-atmosphere-coupled general circulation models, and start from pre-industrial control simulation (picontrol), but with $\mathrm{CO}_{2}$ concentration that is 4 times that of picontrol ${ }^{3}$. The first 150 years of the abrupt $4 \mathrm{xCO}_{2}$ simulations were analysed, focusing on the JAS period. Anomalies are computed relative to the pre-industrial control simulations. We used 26 models for the analysis of Abrupt $4 \times \mathrm{CO} 2$ and picontrol experiments, see Supplementary Table 1. One member is used for each model.

\section{Historical and SSP585 experiments}

The effect of climate change on Sahel precipitation is assessed using historical simulations and SSP585 projections. Historical simulations are forced with observed natural and anthropogenic forcings from 1850 to 2014. SSP585 projections are forced considering a high emission scenario, 
with a forcing of $8.5 \mathrm{~W} \mathrm{~m}^{-2}$ in $2100{ }^{18}$. Effects of climate change are defined as the difference between the period 2060-2099 under the SSP585 emission scenario and the period 1960-1999 under historical emissions, for the JAS season. The time-evolution of precipitation and temperature is also shown, for each JAS season, relative to the period 1960-1999. We used 26 models for the analysis of SSP585 and historical experiments. One member is used for each model.

\section{SSP534_over experiments}

The effect of a mitigation scenario is assessed using historical and SSP534_over emission scenarios. SSP534_over follows SSP585 through 2040 at which point aggressive mitigation is undertaken to rapidly reduce emissions to zero by about 2070 and to net negative levels thereafter ${ }^{18} .7$ models were used, see Supplementary Table 1.

\section{Timescales of response}

Definitions. The climate response to forcing is understood in terms of contributions from two timescales, the fast and slow responses. We defined the fast and slow responses from the abrupt $4 \times \mathrm{CO}_{2}$ and picontrol experiments ${ }^{27,28}$. The fast response is defined as the difference in JAS mean climate, in years 5 to 10 of abrupt $4 \times \mathrm{CO} 2$ relative to the preindustrial climatology. The slow response is defined as the difference between years 120 to 139 to abrupt4xCO2 and the fast response ${ }^{27}$. Here, we applied this methodology to tropical precipitation. We analyse changes in Sahel precipitation due to an abrupt $\mathrm{CO}_{2}$ quadrupling, relative to pre-industrial conditions: precipitation increases strongly during the first 20 years after $\mathrm{CO} 2$ quadrupling, then slowly decreases towards an asymptote which it approaches around a century after $\mathrm{CO} 2$ quadrupling (Supplementary Fig. 9). These results are consistent with a previous study ${ }^{27}$, showing that the years 5-10 and years 120-139 threshold are relevant for the analysis of the Sahel precipitation change.

\section{Timescales of response}

Contributions to SSP585. The contributions of fast and slow timescales were estimated via their distinct patterns of surface warming. The response to the SSP585 emission scenario $\left(\Delta T_{\text {ssp }}\right)$ is spatially regressed (weighted by surface area) on the surface-warming patterns associated with the fast and slow responses (Fig. 1a, b), after ${ }^{27}$ :

$\Delta T_{\text {ssp }}(t)=F(t) \frac{\Delta T_{\text {fast }}}{\overline{\Delta T_{\text {fast }}}}+S(t) \frac{\Delta T_{\text {slow }}}{\overline{\Delta T_{\text {slow }}}}+r(t)$

The regression is performed for each year $t . F, S$ and $r$ are obtained by a multiple linear regression, where $r$ is an intercept, considered as residual. By definition, $F, S$ and $r$ coefficients are in $K$. The coefficient can be interpreted as the contribution of the fast and slow responses to global mean warming in SSP585.

The response in precipitation change is defined by multiplying fast and slow responses in precipitation change (Fig. 1c, d), that is scaled by unit warming, by the corresponding $F$ and $S$ coefficients (Fig. 2a).

\section{Limitations of the method}

A caveat of the study is the uncertainty in reconstructing precipitation change over Sahel, because of the strong assumption of the method, in assuming that Sahel precipitation change could directly scale to changes in global mean surface temperature change. However, the method shows relatively good results in reproducing the pattern in precipitation change and multi-decadal trends in precipitation.

\section{DATA AVAILABILITY}

CMIP6 GCM output is available from public repositories, including https://esgf-index1. ceda.ac.uk/search/cmip6-ceda/.

\section{CODE AVAILABILITY}

Codes are available upon reasonable request to the corresponding author.
Received: 14 November 2020; Accepted: 9 March 2021; Published online: 06 April 2021

\section{REFERENCES}

1. Meehl, G. A. et al. THE WCRP CMIP3 multimodel dataset: a new era in climate change research. Bull. Am. Meteorol. Soc. 88, 1383-1394 (2007).

2. Taylor, K. E., Stouffer, R. J. \& Meehl, G. A. An overview of CMIP5 and the experiment design. Bull. Am. Meteorol. Soc. 93, 485-498 (2012).

3. Eyring, V. et al. Overview of the Coupled Model Intercomparison Project Phase 6 (CMIP6) experimental design and organization. Geosci. Model Dev. 9, 1937-1958 (2016).

4. Monerie, P.-A., Sanchez-Gomez, E. \& Boé, J. On the range of future Sahel precipitation projections and the selection of a sub-sample of CMIP5 models for impact studies. Clim. Dyn. https://doi.org/10.1007/s00382-016-3236-y (2016).

5. Yan, Y., Lu, R. \& Li, C. Relationship between the future projections of Sahel rainfall and the simulation biases of present South Asian and Western North Pacific rainfall in summer. J. Clim. 32, 1327-1343 (2018).

6. Monerie, P.-A., Wainwright, C. M., Sidibe, M. \& Akinsanola, A. A. Model uncertainties in climate change impacts on Sahel precipitation in ensembles of CMIP5 and CMIP6 simulations. Clim. Dyn. 55, 1385-1401 (2020).

7. Almazroui, M. et al. Projected change in temperature and precipitation over Africa from CMIP6. Earth Syst. Environ. https://doi.org/10.1007/s41748-020-00161-x (2020).

8. Park, J.-Y., Bader, J. \& Matei, D. Northern-hemispheric differential warming is the key to understanding the discrepancies in the projected Sahel rainfall. Nat. Commun. 6, 5985 (2015).

9. Fontaine, B., Roucou, P. \& Monerie, P. -A. Changes in the African monsoon region at medium-term time horizon using 12 AR4 coupled models under the A1b emissions scenario. Atmos. Sci. Lett. 12, 83-88 (2011).

10. Biasutti, M. Forced Sahel rainfall trends in the CMIP5 archive. J. Geophys. Res. Atmos. 118, 1613-1623 (2013).

11. Monerie, P.-A., Fontaine, B. \& Roucou, P. Expected future changes in the African monsoon between 2030 and 2070 using some CMIP3 and CMIP5 models under a medium-low RCP scenario. J. Geophys. Res. 117, D16111. https://doi.org/10.1029/ 2012JD017510 (2012).

12. Fontaine, B., Monerie, P.-A., Gaetani, M. \& Roucou, P. Climate adjustments over the African-Indian monsoon regions accompanying Mediterranean Sea thermal variability. J. Geophys. Res. Atmos. 116, n/a-n/a (2011).

13. Roehrig, R., Bouniol, D., Guichard, F., Hourdin, F. \& Redelsperger, J.-L. The present and future of the West African monsoon: a process-oriented assessment of CMIP5 simulations along the AMMA transect. J. Clim. 26, 6471-6505 (2013).

14. James, R., Washington, R. \& Jones, R. Process-based assessment of an ensemble of climate projections for West Africa. J. Geophys. Res. Atmos. 120, 1221-1238 (2015).

15. Diallo, I. et al. Projected changes of summer monsoon extremes and hydroclimatic regimes over West Africa for the twenty-first century. Clim. Dyn. 47, 3931-3954 (2016).

16. Akinsanola, A. A. \& Zhou, W. Projections of West African summer monsoon rainfall extremes from two CORDEX models. Clim. Dyn. 52, 2017-2028 (2019).

17. Dunning, C. M., Black, E. \& Allan, R. P. Later wet seasons with more intense rainfall over Africa under future climate change. J. Clim. 31, 9719-9738 (2018).

18. O'Neill, B. C. et al. The Scenario Model Intercomparison Project (ScenarioMIP) for CMIP6. Geosci. Model Dev. 9, 3461-3482 (2016).

19. Akinsanola, A. A. \& Zhou, W. Ensemble-based CMIP5 simulations of West African summer monsoon rainfall: current climate and future changes. Theor. Appl. Climatol. https://doi.org/10.1007/s00704-018-2516-3 (2018).

20. Monerie, P.-A., Sanchez-Gomez, E., Gaetani, M., Mohino, E. \& Dong, B. Future evolution of the Sahel precipitation zonal contrast in CESM1. Clim. Dyn https://doi.org/10.1007/s00382-020-05417-w (2020).

21. Biasutti, M. Rainfall trends in the African Sahel: characteristics, processes, and causes. Wiley Interdiscip. Rev. Clim. Chang. 10, e591 (2019).

22. Sultan, B. et al. Robust features of future climate change impacts on sorghum yields in West Africa. Environ. Res. Lett. 9, 104006 (2014).

23. Akinsanola, A. A., Zhou, W., Zhou, T. \& Keenlyside, N. Amplification of synoptic to annual variability of West African summer monsoon rainfall under global warming. npj Clim. Atmos. Sci. 3, 21 (2020).

24. Gaetani, M. et al. West African monsoon dynamics and precipitation: the competition between global SST warming and $\mathrm{CO}_{2}$ increase in CMIP5 idealized simulations. Clim. Dyn. 48, 1353-1373 (2017).

25. Hill, S. A., Ming, Y. \& Zhao, M. Robust responses of the Sahelian hydrological cycle to global warming. J. Clim. 31, 9793-9814 (2018).

26. $\mathrm{Ma}$, J. et al. Responses of the tropical atmospheric circulation to climate change and connection to the hydrological cycle. Annu. Rev. Earth Planet. Sci. 46, 549-580 (2018). 
27. Ceppi, P., Zappa, G., Shepherd, T. G. \& Gregory, J. M. Fast and slow components of the extratropical atmospheric circulation response to $\mathrm{CO}_{2}$ forcing. J. Clim. 31, 1091-1105 (2017).

28. Zappa, G., Ceppi, P. \& Shepherd, T. G. Time-evolving sea-surface warming patterns modulate the climate change response of subtropical precipitation over land. Proc. Natl Acad. Sci. USA 117, 4539 LP-4545 (2020).

29. Chadwick, R., Ackerley, D., Ogura, T. \& Dommenget, D. Separating the influences of land warming, the direct $\mathrm{CO}_{2}$ effect, the plant physiological effect, and SST warming on regional precipitation changes. J. Geophys. Res. Atmos. 124, 624-640 (2019).

30. Webb, M. J. et al. The Cloud Feedback Model Intercomparison Project (CFMIP) contribution to CMIP6. Geosci. Model Dev. 10, 359-384 (2017).

31. Good, P. et al. A step-response approach for predicting and understanding nonlinear precipitation changes. Clim. Dyn. 39, 2789-2803 (2012).

32. Lucarini, V., Ragone, F. \& Lunkeit, F. Predicting climate change using response theory: global averages and spatial patterns. J. Stat. Phys. 166, 1036-1064 (2017).

33. Monerie, P.-A., Sanchez-Gomez, E., Pohl, B., Robson, J. \& Dong, B. Impact of internal variability on projections of Sahel precipitation change. Environ. Res. Lett. 12, (2017).

34. Ackerley, D. et al. Sensitivity of twentieth-century sahel rainfall to sulfate aerosol and $\mathrm{CO}_{2}$ forcing. J. Clim. 24, 4999-5014 (2011).

35. Gaetani, M., Janicot, S., Vrac, M., Famien, A. M., \& Sultan, B. Robust assessment of the time of emergence of precipitation change in West Africa. Sci. Rep. 10, 7670 (2020).

36. Taylor, C. M. et al. Frequency of extreme Sahelian storms tripled since 1982 in satellite observations. Nature 544, 475-478 (2017).

37. Rowell, D. P., Fitzpatrick, R. G. J., Jackson, L. S. \& Redmond, G. Understanding inter-model variability in future projections of a Sahelian storm proxy and South Saharan warming. J. Clim. https://doi.org/10.1175/JCLI-D-20-0382.1 (2020).

38. Giannini, A. \& Kaplan, A. The role of aerosols and greenhouse gases in Sahel drought and recovery. Clim. Chang. 152, 449-466 (2019).

39. Marvel, K., Biasutti, M. \& Bonfils, C. Fingerprints of external forcing agents on Sahel rainfall: aerosols, greenhouse gases, and model-observation discrepancies. Environ. Res. Lett. 15, 084023 (2020).

40. Keller, D. P. et al. The Carbon Dioxide Removal Model Intercomparison Project (CDRMIP): rationale and experimental protocol for CMIP6. Geosci. Model Dev. 11, 1133-1160 (2018).

41. Hawkins, E. \& Sutton, R. The potential to narrow uncertainty in projections of regional precipitation change. Clim. Dyn. 37, 407-418 (2011).

42. Rowell, D. P. Sources of uncertainty in future changes in local precipitation. Clim. Dyn. 39, 1929-1950 (2012).

43. Fontaine, B., Janicot, S. \& Monerie, P.-A. Recent changes in air temperature, heat waves occurrences, and atmospheric circulation in Northern Africa. J. Geophys. Res. Atmos. 118, (2013).

44. Parkes, B., Cronin, J., Dessens, O. \& Sultan, B. Climate change in Africa: costs of mitigating heat stress. Clim. Chang. 154, 461-476 (2019).

45. Ahmadalipour, A., Moradkhani, H. \& Kumar, M. Mortality risk from heat stress expected to hit poorest nations the hardest. Clim. Chang. 152, 569-579 (2019).

46. Sultan, B. \& Gaetani, M. Agriculture in West Africa in the twenty-first century: climate change and impacts scenarios, and potential for adaptation. Front. Plant Sci. 7, 1262 (2016).
47. Forster, P. M., Maycock, A. C., McKenna, C. M. \& Smith, C. J. Latest climate models confirm need for urgent mitigation. Nat. Clim. Chang. 10, 7-10 (2020).

\section{ACKNOWLEDGEMENTS}

The authors thank the three anonymous reviewers for their constructive comments and suggestions. We acknowledge the World Climate Research Programme, which, through its Working Group on Coupled Modelling, coordinated and promoted CMIP6. We thank the climate modelling groups for producing and making available their model output, the Earth System Grid Federation (ESGF) for archiving the data and providing access and the multiple funding agencies who support CMIP6 and ESGF.

\section{AUTHOR CONTRIBUTIONS}

P.-A.M. conceived the study, performed the analysis and led the writing. B.P and M.G. contributed to the design of the study, discussed the results and contributed to writing of the manuscript.

\section{COMPETING INTERESTS}

The authors declare no competing interests

\section{ADDITIONAL INFORMATION}

Supplementary information The online version contains supplementary material available at https://doi.org/10.1038/s41612-021-00179-6.

Correspondence and requests for materials should be addressed to P.-A.M.

Reprints and permission information is available at http://www.nature.com/ reprints

Publisher's note Springer Nature remains neutral with regard to jurisdictional claims in published maps and institutional affiliations.

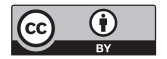

Open Access This article is licensed under a Creative Commons Attribution 4.0 International License, which permits use, sharing, adaptation, distribution and reproduction in any medium or format, as long as you give appropriate credit to the original author(s) and the source, provide a link to the Creative Commons license, and indicate if changes were made. The images or other third party material in this article are included in the article's Creative Commons license, unless indicated otherwise in a credit line to the material. If material is not included in the article's Creative Commons license and your intended use is not permitted by statutory regulation or exceeds the permitted use, you will need to obtain permission directly from the copyright holder. To view a copy of this license, visit http://creativecommons. org/licenses/by/4.0/.

(c) The Author(s) 2021 